\title{
Educación y Conflictos sociales
}

\section{Ponencia de inauguración presentada en Seminario sobre Articulación de obras del sector educativo de la Compañía de Jesús}

\section{7 de febrero de 2020}

Gustavo Calderón SJ. ${ }^{24}$ Provincial de la Compañía de Jesús en Ecuador prov-ecu@jesuitas.ec

Artículo recibido en noviembre y aprobado en diciembre 2020

\section{Resumen}

Formar para la ciudadanía global es el punto central de la reconstrucción del pacto educativo global planteado por el Papa Francisco. Esta invitación nos mueve a las obras educativas de la Compañía de Jesús en Ecuador a reflexionar sobre nuestro rol en estos tiempos de conflictos sociales vividos en el país y en el mundo. Necesitamos repensar la educación para una nueva ciudadanía comprometida con la transformación de las problemáticas del mundo de hoy. Este constituye un eje articulador desde donde debemos seguir fortaleciendo nuestras obras y programas educativos.

Palabras clave: ciudadanía global, Compañía de Jesús, educación, conflictos sociales.

24 Maestría en Teología-Boston College, Boston-EEUU. Licenciado en Ciencias Políticas y Sociales - Universidad Católica de Guayaquil. Rector Unidad Educativa Javier - 1999 - 2011. Delegado de Educación de la Compañía de Jesús - 2003 - 2007. Delegado de Formación de la Compañía de Jesús - 2008 - 2017. Provincial de la Compañía de Jesús desde 2017. 


\section{Education and Social Conflicts \\ Opening paper presented at Seminar on Articulation of Works of the Educational Sector of the Society of Jesus}

\section{Abstract}

Training for global citizenship is the central point of the reconstruction of the Global Compact on Education proposed by Pope Francis. This invitation moves us to the educational works of the Society of Jesus in Ecuador to reflect on our role in these times of social conflict experienced in the country and in the world. We need to rethink education for a new citizenship committed to the transformation of the problems of today's world. This constitutes an articulating axis from which we must continue to strengthen our educational works and programs.

Keywords: global citizenship, Society of Jesus, education, social conflicts.

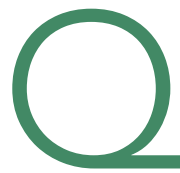

ueridos compañeros y compañeras en la misión El Papa Francisco nos ha invitado a reconstruir un pacto global educativo. La pregunta que está en el centro de la propuesta es ¿qué significa formar un ciudadano global? Insiste, en que "hoy más que nunca, es necesario unir los esfuerzos por una alianza educativa amplia para formar personas maduras, capaces de superar fragmentaciones y contraposiciones y reconstruir el tejido de las relaciones por una humanidad más fraterna" (Francisco, 2019, párr. 2). Su invitación es a buscar "un camino educativo que haga madurar una nueva solidaridad universal y una sociedad más acogedora" (Francisco, 2019, párr.1).

Esta mañana queremos crear un espacio de reflexión sobre la clase de educación que ofrecemos, cuando vivimos tiempos de crisis y conflictos sociales en el mundo entero. Las protestas de octubre 2019 en Ecuador, y diversas manifestaciones ocurridas en América Latina particularmente, nos cuestionan sobre el rol de nuestras instituciones educativas. 
El Padre General de los Jesuitas, Arturo Sosa SJ, se reunió en marzo del 2019 con exalumnos de nuestras obras educativas en la India y les hablaba sobre lo que se espera de ellos al haberse formado desde la espiritualidad y pedagogía ignacianas. Llamaba su atención diciéndoles que les correspondía ser actores protagónicos en situaciones complejas. Aquí sus palabras:

Pobreza, conflictos violentos y desastres naturales obligan a un gran número de personas a huir de sus hogares para emprender una vida nueva en otra parte. Estos migrantes y refugiados tienen que hacer frente a enormes desafíos en su peregrinaje. No podemos permanecer indiferentes ante su difícil situación...

Nos esforzamos por levantar unas estructuras de apoyo, que ayuden a las comunidades marginadas a alcanzar un nivel de vida razonable. Al mismo tiempo, pretendemos formar la conciencia personal, promoviendo una cultura de la fraternidad y la aceptación...

La reconciliación con la creación se ha convertido en una nueva urgencia de nuestro tiempo. Es algo que requiere un enfoque plural capaz de cuestionar los modelos de desarrollo al uso y favorecer un mayor respeto por la creación de Dios. A nivel más amplio queremos unir nuestras fuerzas a las de expertos en la tarea de detectar cuáles son las raíces y cuáles las soluciones a la crisis ecológica. Y no podemos obviar la necesidad de revisar nuestros propios patrones de consumo para adoptar un estilo de vida que refleje nuestro ideal. (Sosa, 2019, párr. 3, 10 y 11)

Las palabras a los ex alumnos nos dan pistas claras de lo que se espera de hombres y mujeres que, insertos en el devenir del mundo actual, debieran involucrarse en la transformación social del mundo. La Compañía de Jesús educa para transformar. Transformar aquellas estructuras que producen injusticia e inequidad.

En el reciente documento "Colegios jesuitas, una tradición viva en el siglo 21. Un ejercicio continuo de discernimiento", se esboza lo que debiera ser nuestra propuesta educativa, claramente expresada en el lema "hombres y mujeres con y para los demás". La educación jesuita 
debe proveer oportunidades para que los estudiantes, además de una competencia profesional óptima, apuesten por los siguientes rasgos:

1. Se formen con corazones abiertos a los sufrimientos de los demás a través del contacto directo;

2. Desarrollen una conciencia crítica que entienda las causas de la desigualdad y la opresión;

3. Ganen en competencia para efectuar cambios positivos en la cultura local y en el mundo;

4. Adquieran resistencia para no desfallecer frente a las incomprensiones y la crítica.

El Congreso Internacional de Fe y Alegría realizado en septiembre de 2018 en El Escorial, España, nos recordaba que esta red de educación popular "educa en las fronteras", en fronteras geográficas y existenciales de este mundo. El Padre General Arturo Sosa decía:

Fe y Alegría es educación formal y, al mismo tiempo, educación ciudadana y corriente de promoción social. Es trabajo con y en la comunidad. Está comprometida con la transformación de las estructuras para mejorar las condiciones de vida de las comunidades, la defensa de los derechos humanos y ampliar la participación ciudadana. Fe y Alegría ofrece una educación que fundamenta el cambio dirigido a construir sociedades libres, democráticas, equitativas, promotoras de paz, en las que la violencia no encuentre lugar. (Sosa, A. 2018, p. 5)

En 1990, cuando el Papa Juan Pablo Il promulgaba la Constitución Apostólica Ex Corde Ecclesiae, afirmaba palabras que muestran un claro horizonte para la educación hoy: "La Universidad Católica deberá tener la valentía de expresar verdades incómodas, verdades que no halagan a la opinión pública, pero que son también necesarias para salvaguardar el bien auténtico de la sociedad." (Juan Pablo II, 1990, párr.32)

A la pregunta que plantea el Papa Francisco, sobre qué significa formar un ciudadano global, él mismo nos ilumina en la Encíclica Laudato sí del año 2015, en el numeral 211, manifestando que una educación seria hoy: 
...está llamada a crear una ciudadanía ecológica. La existencia de leyes y normas no es suficiente a largo plazo para limitar los malos comportamientos, aun cuando exista un control efectivo. Para que la norma jurídica produzca efectos importantes y duradores, es necesario que la mejor parte de los miembros de la sociedad la haya aceptado a partir de motivaciones adecuadas, y que reaccione desde una transformación personal. Sólo a partir del cultivo de sólidas virtudes es posible la donación de sí en un compromiso ecológico. (Francisco, 2015, párr. 211)

Sólidas virtudes. Profundos cambios en nuestros hábitos de vida. ¿Cómo la currícula garantiza esto? ¿Cómo educamos para la paz y la reconciliación que se hace justicia? ¿Cómo formamos para la verdad, la transparencia y la colaboración? Necesitamos una educación conectada con la historia y que sea capaz de proponer respuestas vigentes a las demandas de hoy.

Quisiera enfatizar, que el verdadero foco de nuestros programas educativos no está en el claustro de las instituciones, sino en los grandes acontecimientos sociales, políticos, económicos, religiosos y de todo tipo que ocurren en la sociedad.

Déjenme terminar con parte del discurso en la Universidad de Santa Clara, California en octubre del 2000, del Padre PETER-HANS KOLVENBACH, Prepósito General de la Compañía de Jesús hasta el año 2008, y que ilustra la mirada jesuítica sobre las protestas de octubre, nuestro posicionamiento y parámetros concretos para considerar aprendizajes.

Los estudiantes tienen que dejar entrar en sus vidas la realidad perturbadora de este mundo, de tal manera que aprendan a sentirlo, a pensarlo críticamente, a responder a sus sufrimientos y a comprometerse con él de forma constructiva. Tendrían que aprender a percibir, pensar, juzgar, elegir y actuar en favor de los derechos de los demás, especialmente de los menos aventajados y de los oprimidos. La pastoral universitaria tiene mucho que hacer para fomentar tal compasión inteligente, responsable y activa, que es la única compasión que merece el nombre de solidaridad. (Kolvenbach, 2000, párr.. 42)

Bienvenidos y bienvenidas, gracias. 


\section{Referencias}

Francisco (2019, 12 de septembre) Mensaje del Santo Padre Francisco para el lanzamiento del Pacto Educativo. Vatican.va. Consultado en: http://www.vatican.va/content/francesco/es/messages/ pont-messages/2019/documents/papa-francesco_20190912_ messaggio-patto-educativo.html

Francisco (2015, 24 de mayo ) Carta Encíclica Laudato Si' del santo padre Francisco sobre El Cuidado de la Casa Común. Vatican. va. Consultado en: http://www.vatican.va/content/francesco/ es/encyclicals/documents/papa-francesco_20150524_enciclicalaudato-si.html

Juan Pablo II (1990, 15 de agosto) Constitución Apostólica Ex Corde Ecclesiae del Sumo Pontífice Juan Pablo II sobre las universidades católicas. Vatican.va. Consultado en: http://www.vatican.va/ content/john-paul-ii/es/apost_constitutions/documents/hf_jp-ii_ apc_15081990_ex-corde-ecclesiae.html

Kolvenbach, P. (2000, 6 de octubre) El servicio de la fe y la promoción de la justicia en la educación universitaria de la Compañía de Jesús de Estados Unidos. Consultado en: https://kolvenbach.jesuitgeneral. org/es/archivo?view=archivos\&catid=11\&subject[0]=7

Sosa, A. (2019, 7 de marzo) Alocución del p. General Arturo Sosa SJ a los antiguos alumnos Bandra, 3 de marzo de 2019. Jesuits. Consultado en: https://www.jesuits.global/es/2019/03/07/ alocucion-del-p-general-arturo-sosa-sj-a-los-antiguos-alumnosbandra-3-de-marzo-de-2019/

Sosa, A. (2018, 29 de septiembre) Educamos en las Fronteras, Fe y Alegría, Movimiento Global. Consultado en: https://www.educatemagis. org/wp-content/uploads/documents/2018/10/Discurso-PadreGeneral-47-Congreso-Internacional-Fe-y-Alegr\%C3\%ADa.pdf

Secretariado de Educación de la Compañía de Jesús (2019, 14 de noviembre) Colegios jesuitas, una tradición viva en el siglo 21. Un ejercicio continuo de discernimiento. InfoSJ. Consultado en: https://infosj.es/publicaciones/15986-colegios-jesuitas-unatradicion-viva-en-el-siglo-2 